\title{
The Lesser Antilles, True Laboratories for the Study of Forest Systems the Evolution (from the Inventory of Plant Species to the Dynamics of the Anthropized Landscapes)
}

\author{
P. Joseph, K. Baillard \\ University of the French West Indies, UMR DEV SPACE-BIORECA, Schœlcher, Martinique \\ Email: Joseph.phil@wanadoo.fr
}

Received 11 August 2016; accepted 26 August 2016; published 29 August 2016

Copyright (C) 2016 by authors and OALib.

This work is licensed under the Creative Commons Attribution International License (CC BY). http://creativecommons.org/licenses/by/4.0/

(c) (1) Open Access

\section{Abstract}

Despite their small size, the French West Indies are characterised by a large number of environments supporting a surprisingly high floristic, ecosystem and landscape diversity. From the foundation of dwelling groups, beginning in the 17th century to the present day, human activities have resulted in the sharp decline of the forest areas. To some extent, the Caribbean forest has become "insularized". Originally, these forests covered the entire islands from the coast to circa 800 meters of altitude, where the environmental conditions permitted the development of forest biocenosis. Survival space for the American Indians and early settlers, despite its gradual weakening and its spatial regression in the 18th and the 19th century and in the first half of the 20th century, the forest ecosystem represented a place of high exploitation of the wood resources in principal for energy, carpentry, cabinetmaking, housing and industry linked to profit-generating crops (sugar cane). Unlike the pre-colonial period where the tree was predominant, the present vegetation is dominated by regressive communities, consisting of shrub and herbaceous communities. Since their origin, the Lesser Antilles have represented special objects of study for naturalists, botanists and systematics scholars, especially concerning the forest ecosystems. They are also true laboratories for the study of vegetation dynamics and the evolution of the man-environment relationships where the landscape is a relevant descriptor. This article aims to show the evolution of knowledge of the structures, functions and spatiotemporal dynamics of the plant ecosystems of the Lesser Antilles. The biocenotic diversity of the vegetation of the islands required the knowledge of species, associations they represent and the bioclimates who influence them. In this context Martinique is a significant example of the ecosystem complexity under anthropogenic stresses.

\section{Keywords}

French West Indies, Forest Ecosystems, Anthropization, Biodiversity, Landscape

How to cite this paper: Joseph, P. and Baillard, K. (2016) The Lesser Antilles, True Laboratories for the Study of Forest Systems the Evolution (from the Inventory of Plant Species to the Dynamics of the Anthropized Landscapes). Open Access $\mathrm{Li}$ brary Journal, 3: e2969. http://dx.doi.org/10.4236/oalib.1102969 


\section{Subject Areas: Biogeography, Ecology, Natural Geography}

\section{Introduction}

The purpose of biogeography is, to some extent, to decrypt the dynamics of biological systems at all scales of biosphere complexity (the world space). In reality the objective is to learn about the structural and factorial organization of the biosystem elements (the ecosphere): from the individual to the ecosystem. In the Lesser Antilles the naturalistic saga began with the inventory and the determination of species, in particular plant species. This means we focus on the systematics, the taxonomy and even on the classification of the phylla or taxa. What we then obtain is a botanical geography linking each species to a given space: without fail we link them to the climate (Figure 1(a)).

Through the specific modes of species grouping, we observed floristic formations differentiable in space. Therefore, the physiognomy characteristics or the morphology of the landscape became a relevant description criterion and led to the inventory of structures. Like other biosphere areas, the island space can be divided into climate types affecting the installation or installation failure of the plant species. This is the situation that defined the different bioclimates for these islands. Using the concepts of biocoenosis, biotope and ecosystem of modern ecology, we were able to connect the main formations to the environmental conditions. Subsequently the concept of functional groups emerged, summarizing the interaction of all the biotic and abiotic parameters of

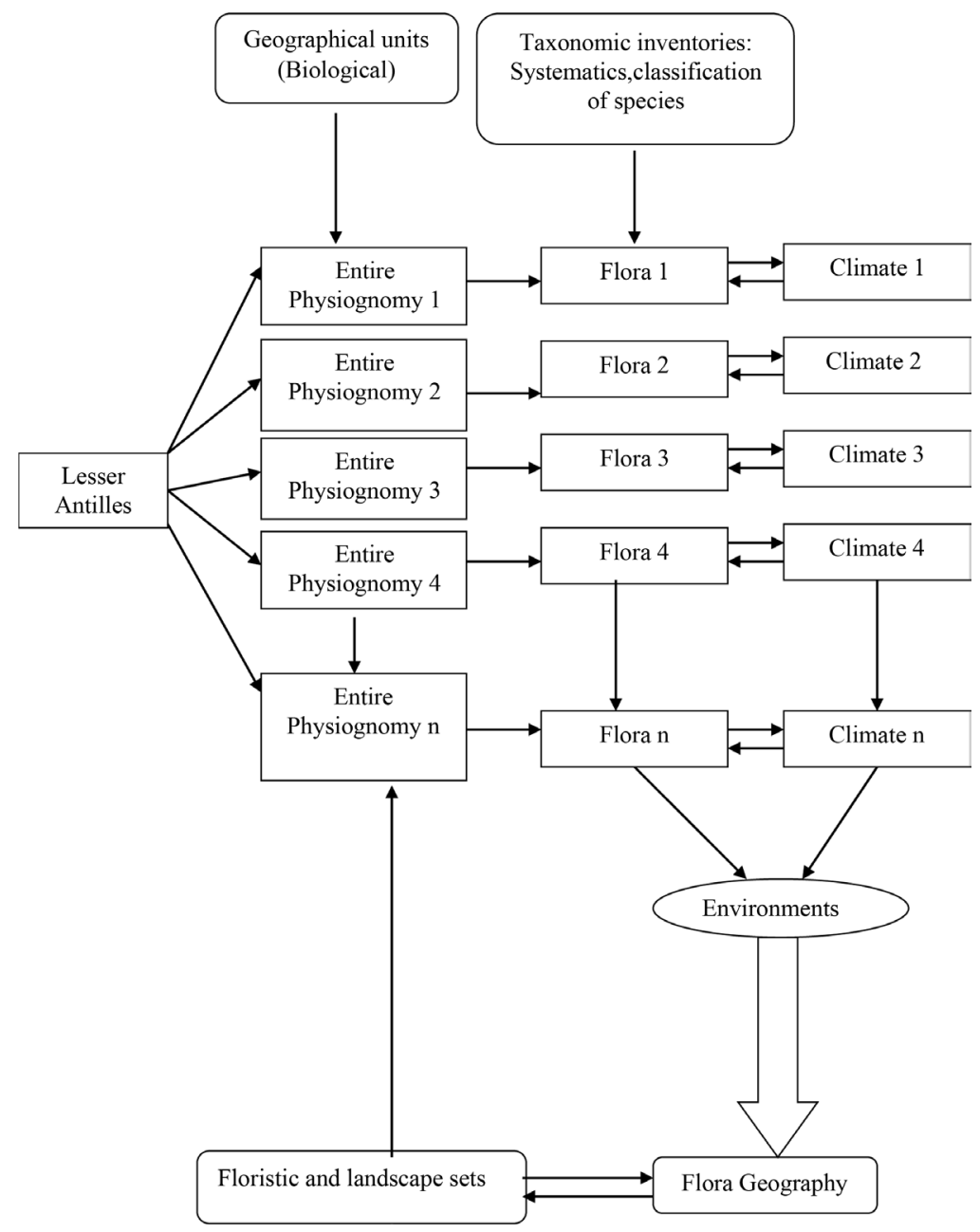

(a) 


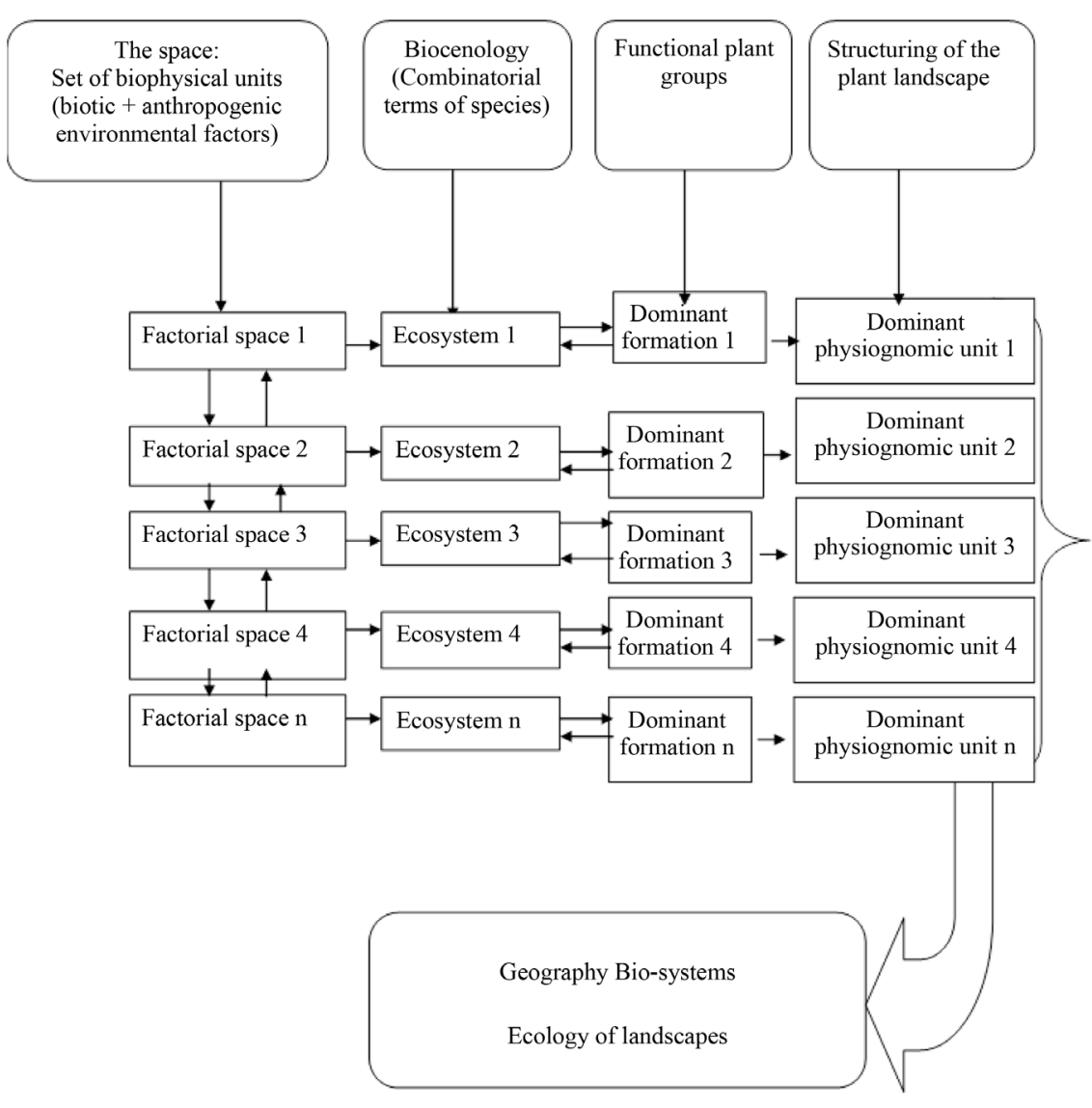

(b)

Figure 1. (a) The Lesser Antilles a complex biophysic formation; (b) the Lesser Antilles complex biophysics structure.

the biotope. In this case, the species composing them specify the bioclimate, the behaviours towards the biophysical factors, the stage of development and the preponderance of morphotypes or physiognomic types (Figure 1(b)).

Like most planetary ecosystems, those of the Lesser Antilles have been influenced by man or anthropized. Their artificialization is consubstantial with the implementation and the evolution of dwelling networks (the French Islands) or plantations (the British Islands). It was therefore necessary to define the limits of ecosystem stages depending on the ecosystems' ability to control or restore themselves (their resilience). The islands of the Caribbean basin are true laboratories for this type of approach, their anthropization is recent and began with the discovery of the Americas and varied in intensity and frequency. In reality the domestication of these lands was strongly differentiated both in space and in time. The ecosystem mosaic we can see today derives from the original forest formations [1] [2]). By combining the information from the ancient chroniclers and naturalist travellers, recent data, the description of landscapes and the synchronic approach we were able to reconstruct the major stages of landscape evolution. The Martinique like the other West Indies suffered, from the 17th century to the present, of the successive waves of human impacts and therefore is a good object of study to decipher the complex relationships existing between the men and the vegetation. From the coast to the summits, this mountainous island induces, the dry subhumid bioclimate, the bioclimate subhumid moist, the humid bioclimate and the hyperhumid bioclimate. At these bioclimates correspond (in different levels of evolution) the following forest potentialities: seasonal tropical dry evergreen forest, moist evergreen tropical seasonal forest, submontane tropical rainforest, montane tropical rainforest.

\section{The First Data}

The scientific literature on the vegetation of the Lesser Antilles is in fact very poor. Even if strongly subjective, 
the descriptions recorded in the accounts of the discoverers and naturalist travellers from the early days of colonization represent the first data on the flora, fauna and landscapes [3]. The various forest uses of the Native Americans were only transcribed. The descriptions of plant physiognomy are essential and serve as a starting point, specifically for the study of the evolution of the vegetation cover from the moment they took possession of it [4]. Many members of the Catholic Church of various faiths participated in the establishment of knowledge regarding the flora of this world's region. Their work, while important to approach the plant diversity of the pre-Columbian era, amounted to rough, sometimes unusable descriptions of the phenological (biological) characteristics of the formations [5].

For today's botanists the absence of determination keys makes it difficult to use these old data. However, some information regarding the plants (the leaf apparatus, the fruit, flowers, morphology), their use by the Native Americans and the general characteristics of the environments have enabled and still allow us to identify a number of tree species. From the seventeenth century, the striking element in the travel narratives is this rapid physiognomic change in the vegetation cover. Logically in congruence with the excessive use of the forest resources, it foreshadowed the establishment of large plantations. The data on deforestation, soil depletion and the progressive drying up of sources and consequently of rivers, especially in the little watered island regions, must be considered within a diachronic approach.

\section{The Inventory of Species}

All the current botanical knowledge of tree species is the result of a long appropriation and classification process. The men who have influenced the botanical history of the Lesser Antilles include: [6]-[46].

These naturalists highly contributed to the inventory of trees in the Lesser Antilles. Through summary descriptions each brought his own small contribution to the botanical knowledge to be gathered. Over time, the number of recorded taxa increased. However, until the middle of the eighteenth century, the absence of a unique classification and the lack of real keys in the field of systematics made inter-island comparisons difficult. Since the inception of his binomial codification, in 1763 Linne named 312 species of the Lesser Antilles. Nevertheless, the botanical knowledge consisted mainly of lists of plants or collections of dry materials. The first botanical books with their imprecise morphological and phenological descriptions, accompanied by some information on the life environment and various uses appear in mid-19th century. These first flores foreshadowing a modern period recorded two centuries and a half of naturalist inventories, descriptions and collections. Data on tree chorology are rarely mentioned and when they exist, they are often unusable: Maycock (the Flora of Barbados [27]), Grisebach (the Flora of the British West Indies: [29]), Duss (the Flora of the French West Indies [30]), Boldingh (the Flora of the Netherlands Antilles [34]). Notwithstanding these imperfections due to the early efforts of what we will later call the natural sciences, these different plant types were essential for the evolution of the naturalist knowledge of this region.

The most complete plant types out of which some are still in use today and which really highlight the modern period of Caribbean botany appear from the second half of the twentieth century. In addition to specific and sometimes complex determinations keys, the descriptive data on the environments characterize their main biogeographic features: Howard (Grenadines [41]); Gooding et al. (Barbados [42]), Proctor (Cayman [45]), Stoffers (Netherlands Antilles [44]), Fournet (French West Indies [43]). If the botanical knowledge of the Lesser Antilles increased significantly between 1700 and 1900, the knowledge regarding the individual functioning and the community of species in relation to their environment was very slowly gathered. The root causes of this situation are to be found in the emerging nature of the ecological sciences.

\section{The Beginning of the Forest Ecology Research}

We can assert, without being too much in the wrong, that the scientific study of the Lesser Antilles forest ecosystems truly begins in the middle of the twentieth century with H. Stehle [38]-[40] for the French West Indies and J. B. Beard [37] for the British West Indies. Their work, even though different both in methodology as well as in the use and analysis of the results, is used as historical references since they have generated the first data on the ecology of native trees. The first concern within a forest formation, was to find floristic indicators in the form of floristic formations or associations that can identify the different units. This research carried out in the early days of the Lesser Antilles forest ecology remained descriptive but not less interesting. The species were defined ecologically based on their temperament (their affinity) for rainfall which resulted in this spatial subdi- 
vision, even more essential today, proposed by the above mentioned authors. Respectively, the doctoral theses of H. Sethle [40] and J. S. Beard [37] are akin to an inventory of the plant communities within climate regions ranging from the dry to the hyper-wet climate including the wet climate and in space ranging from the coasts to the high altitude forests.

The different expressions of the vegetal cover are all taken into account, no matter how poorly positioned in time. We still perceive the diversity of plant combinations. Naturally, the conceptual field of time in matters of ecology did not permit the quantitative exploration of the determinants that control this synecological diversity. The definition of the determining climate zones in the installation of the plant species, the dominant formations and information on their temperament, their adaptive modes, their morphology and their architecture were all elements that formed the basis for an ecological research in the islands of the Caribbean basin. H. Sethle [38]-[40] despite his genius in botany and botanical geography, was extremely vague concerning his survey stations and temporal arrangement of the formations, although they correctly specified the described biotopes. Sethle's monumental work is somewhat undermined by a permanent lack of methodological rigor. It should be noted that at this time the inefficient inventory techniques were not standardized. Yet many of today's proven functional processes had already been envisaged, including those related to plant succession.

Conversely, J. B. Beard [37] was highly accurate both regarding the geographic location of the stations and the presentation of the results. The conclusions reflected in his doctoral thesis using the English West Indies as a study area are valid for the whole of the Lesser Antilles. Without too many details, it clearly shows the differences in the inter-island ecosystem potentiality and through the floristic groups, it already forecasts the major phases of the evolution of the vegetal cover. The structural aspects are just as interesting especially the biomass estimated through the basal surface. Obviously due to their intuition and their knowledge of the Lesser Antilles forest environments these two researchers produced new data and are the true founders of forest ecology in this part of the world. During much of the second half of the twentieth century Sethle and Beard remained essential scientific references. It should be noted that the craze for ecology research was much stronger elsewhere in the Tropics (America, Africa, Asia). To a certain extent the Caribbean Islands were abandoned at that time.

\section{New Approaches}

\subsection{A Determining Synthesis}

It is the doctoral thesis of J Portecop [47] that gives us another phyto-ecologic and biogeographical research dynamics. This work is a structured synthesis incorporating all the issues dealt with by H. Sethle [40], to which he adds new field data. Using modern methodology and data processing, he revisits a certain number of concepts, in principal those concerning the major forest types and vegetation dynamics. Like the previously cited researchers, the different environments as well as their multiple facies are defined by specific species the formations. Here he shows the extreme complexity of the mechanisms linked to the evolution of the vegetation. The intimate relationship between bioclimate and floristic expressions is clear (Figure 1(b)). The great merit of Jacques Portecop' work was to intelligibly present the complex knowledge where he reconsidered several few aspects. In addition to the structural and functional plant cover complexity, the absence of a flora rendered the determinations difficult. Undeniably his contribution to the knowledge of the functioning of the Lesser Antilles island ecosystems was crucial and influenced the subsequent research. In fact, until today, in the French West Indies in particular, his conclusions or even his iconographic documents serve as reference for the territorial planning issues.

\subsection{The Current Period: Between Architecture, Structure and Successional Processes}

As for all of the elements life, the evolution of botanical and ecological knowledge is a punctual and non-continuous evolution: And this is particularly true for our climates. At the end of the twentieth century, Jean Pierre Fiard, Professor of philosophy in the secondary education system and naturalist, will, somehow, revolutionize the naturalist knowledge of Martinique and more broadly that of the Lesser Antilles. As an informed amateur, associated with a specialist in the London Botanical Garden D. N. Pegler [48], he began by studying the higher mushrooms in Martinique: The macrofungi agaricoides [49]. This work was crowned by the publication of the first flora of higher fungi in Martinique. After this first experience, revealing a rich and specific vegetation community, he was logically interested in forest trees. The task was not an easy one due to the lack of determining keys for the phanerogamic flora of A. Duss [30]. 
At the same time, the commitment of Gérard Chauvin [50]-[52] geographer also working in the secondary education, was very important for the evolution of naturalist knowledge in Martinique and in the Lesser Antilles. His main contribution, and not the least important, was the publication of several systematics books allowing the precise determination of the botanical species irrespective of their physiognomic type. The problem of the tree species inventory being solved, after several years of herborization, J. P. Fiard took an interest in the operation of forest communities. The help of Bernard Rollet [53] prominent scholar of continental and insular tropical forests, was essential.

At the beginning of the 9th decade of the last century, under the direction of Professor J. Portecop [47] J. P. Fiard [1] presented a doctoral thesis on the ecology of the forests of the Northwestern slopes of Mount Pelé. This monumental work in some respects unknown to the national scientific world is innovative since it proposes new ideas and new concepts, supported by unusual highly accurate field data. His demonstration uses the ancient forests as its context, perhaps the climax wet and moderately humid ones in the northern area of Martinique between the communes of Grand' Riviére and Precheur. This area is characterised by a plant continuum, from the marine surf to the top, where the forests can grow. J. P. Fiard considers their bioclimatic, architectural, structural, floristic, biocenotic, edaphic and dynamic aspects. To use even stronger explanatory models, he carried out comparative studies in St. Lucia, St. Vincent, Dominica, Guadeloupe, Saint Martin, les Saintes and Marie Galante. The mass of generated data is still insufficiently used nowadays. In fact for this man of literary education, this is a descriptive and analytical work, a structured, rigorous and intelligible work of extreme scientific quality, addressing almost all the global functional traits of the forest vegetation.

In 1986, I (P. Joseph) join the circle of botanists and ecologists of the Lesser Antilles. Very rapidly I engage in the study of Martinique's flora. First within the ZNIEFF (Natural Areas of Ecological Floristics and Fauna Interest) program under the auspices of the Gallery of Botany of the Fort-de-France town. This long and tedious work gave me the opportunity to acquire a solid knowledge of plant species: irrespective of their physiognomic type. This period corresponded to the time when J. P. Fiard carried out his forest research work; it allowed me to take part in all his floristic inventories. Then, in the context of a doctoral thesis in ecology and biogeography, I studied the successional processes specific to Martinique's vegetation understorey conditioned by the dry bioclimate. The complexity of this research lay in the deeply heterogeneous nature of these plant formations due to societal development (from dwellings to today's houses). The main dynamics stages associated with specific plant species have been decrypted as well as their ecological profiles. I also attempted to reconstruct the evolution of landscapes from pre-Columbian times to the present day (Figure 1(a) \& Figure 1(b)).

The vegetation's modifier role with regard to the macroclimate, during the positive succession, the vegetation inversion mechanisms frequently due to the topographic model and modalities for diaspora dissemination were discussed, analysed and sometimes proven. Even if the overall conclusions deal with the low areas of the island of Martinique, they can nevertheless be extrapolated both to Martinique's other bioclimates and to the other components of the Lesser Antilles. To generalize the proposed concepts, after the theories were developed and the data collected in Martinique was extrapolated, surveys were carried out in other entities of the archipelago, either mountainous [Guadeloupe (Basse-Terre), St. Lucia, Dominica, St. Vincent], low (Marie-Galante, GrandeTerre of Guadeloupe) or low altitudes ones (the Saintes). Despite the existence of common functional mechanisms, these comparative studies allowed us to understand the great biocenotic variety of the plant cover of this archipelagic system. In total, compared with my predecessors, my doctoral work supplied new bases or reconsidered concepts and methodologies in a new light, enabling us to approach the structural and dynamic complexity of plant formations by including human activities (Figure 2).

The above mentioned specialists are joined by others who participated or even today contribute to the enrichment of the naturalistic and ecological knowledge of our region. They are interested in very specific aspects of ecophysiology, phytogeography, conservation biology, of the link between climate, vegetation and avifauna [54] [55].

Despite their highly specialized nature, these works have the merit of supplying data to the models while reinforcing them. In the Lesser Antilles, apart from the local researchers or residents belonging to the University of the West Indies and that of the West Indies, some foreign researchers (Canadian, American, English, Dutch) and from mainland France as well as some institutes working on connected singular aspects (IRD, INRA, the National Museum of natural history), nobody believes that the plant biosystems are a vital research axis. Therefore, compared to the great inter-tropical biomes of global importance, the small islands of the Antilles are considered little diversified and little complex, since they have already been adequately studied in the past. 


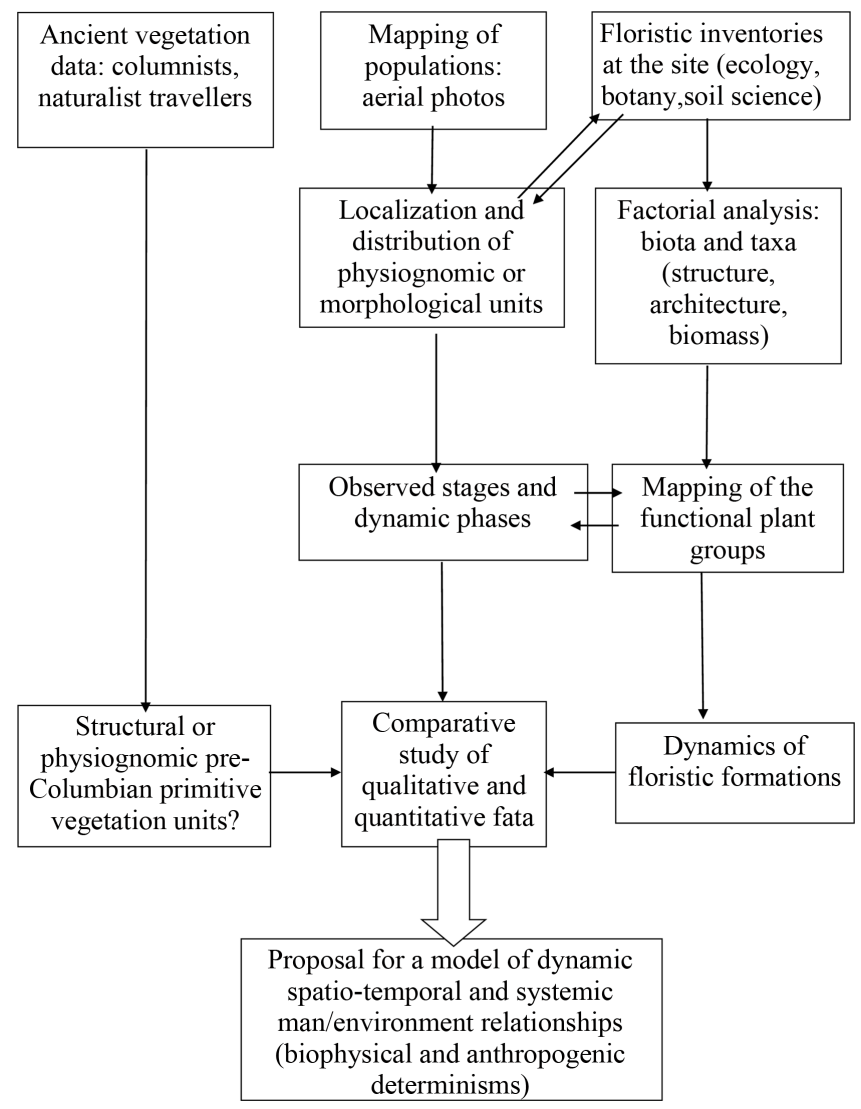

Figure 2. Methodology and exploratory tools.

Given the precarious conditions of exercising scientific research in Europe and particularly in France, the global nature sciences, based in some respects on archaic disciplines compared the new sciences of living things such as genetic engineering, are little promoted and funded. In this context our little islands, marginal elements within the biosphere, are almost irrelevant. Yet they are true in-situ conservatories and laboratories, a small but essential part of life, filled with countless floristic, ecosystem and landscape riches. The factorial complexity results in a multitude of biotic communities, great plant diversity, floristic endemism, spatially uneven intensity and frequency of the anthropization which represent as many parameters that turn these tiny bits of biosphere into dense ecosystem mosaics. These islands make excellent objects of study on all spatial and temporal scales, for the disciplines concerned with the relationship between Human Society and Nature. Finally, their small size and their alleged low complexity and biological diversity render them approachable research objects on the human scale.

\section{Botanical and Biocenotic Geography}

The study of the spatial plant distribution and phytocenoces is complicated due to the significant heterogeneity of the environments. The spatial variations of the physical parameters represent the origin of many biotopes affecting a wide variety of plant formations. The main bioclimates defined here by the pluviometric gradient have always been taken into account to determine the various plant floors as well as the ecology of the endemic plant species. In reality things are not that simple. In the light of forest inventories, we see the extremely discontinuous distribution of species populations [2] [37] [40] [47] [54]. While we can subdivide the collection of forest taxa (the forest floristic potential) in three broad classes of bioclimatic temperaments (xerophytic, mesophilic and hygrophilous), on the other hand, it is difficult to predict their community or biocenotic means.

The ability of a given species to colonize an environment (a bioclimate) forms the basis of this phenomenon. Although it is spatially delimited and defined by average values, the bioclimate is a mesh of meso-climats that can be broken down into smaller units: microclimates [2]. In fact, these bioclimates create a more or less dense 
set of environments selecting the environmentally adapted species. The geographic distribution of a taxon within the plant floor and therefore within a bioclimate will depend on its skills to settle and to regenerate in different micro-environments. Then we see the interspecific relations (biotic interactions) taking place, they will affect the populations size.

In addition to the spatial heterogeneity of the environmental factors, we must take into account the temporal heterogeneity regarding the varying development degrees of the floristic and ecological units. Except for the rare relict forests, the present vegetation is an interactive assembly of vegetation groups with different floristic composition, structure, architecture and ages (Figure 3). More than those of the Lesser Antilles' prehistory, today's plant cover represents complex and dense spatio-temporal mosaics. The presence and the ecological importance of taxa depend both on the abiotic and biotic infra-site factors and on the effectiveness of the diaspora (seed) dissemination.

At supra-site scale this high heterogeneity of the ecological conditions in time and space is an almost insurmountable obstacle to the definition of plant formations. In the vast majority of cases, the inventory of a forest massif, whose environmental conditions are generally homogeneous, does not allow us to obtain a formation of two or three ecologically dominant species. There is often a group of main taxa which match an average value of the differences in site dominance. Accordingly, the large scale mapping of the floristic formations using plant binomials or trinomials is almost impossible and ineffectual when confronted with the reality in the field. And this fact applies to the so-called ancient or climax forest communities as well. Solely due to their many constituent phytocenoses shaped by human activities, the multiple ecological units that structure today's landscape cannot be precisely mapped. To render them intelligible, we must base the future maps on the general characteristics of the forest types, declining their ecosystem potential, their bioclimatic determinisms, their overall stage of evolution as well as the various possible floristic combinations of the site.

The ancient biogeographical descriptions of the Lesser Antilles forested areas, with associations of a very small number of species (two and in addition three), irrespective of their level of development, represent just unique facets of phytocenotic diversity. We believe that the dynamics series and other successional chrono-sequences of the old authors used to define the plant formations are very reductive. From the plant succession point of view, there are species with an almost identical ecological profile that develop populations in the same stages. Only small variations in biophysical factors (topographic, edaphic, micro climatic, biotic) and micro-environments will operate differences in terms of ecological dominance and therefore in terms of demographic success. This differentiation, both specific and biocenotic, is all the more striking as the anthropogenic transformations are deep.

The above mentioned ideas show the difficulty we have in establishing a geographic and ecosystem botany in these highly artificial island systems. It is extremely difficult to propose global diagrams able to present the reality with a minimum of accuracy. As such, the valuable data of our predecessors must be reinterpreted by integrating them into an approach aimed at a more comprehensive exploration.

\section{Anthropization}

Just like the anthropized tropical islands, the Lesser Antilles have undergone profound ecological changes. The

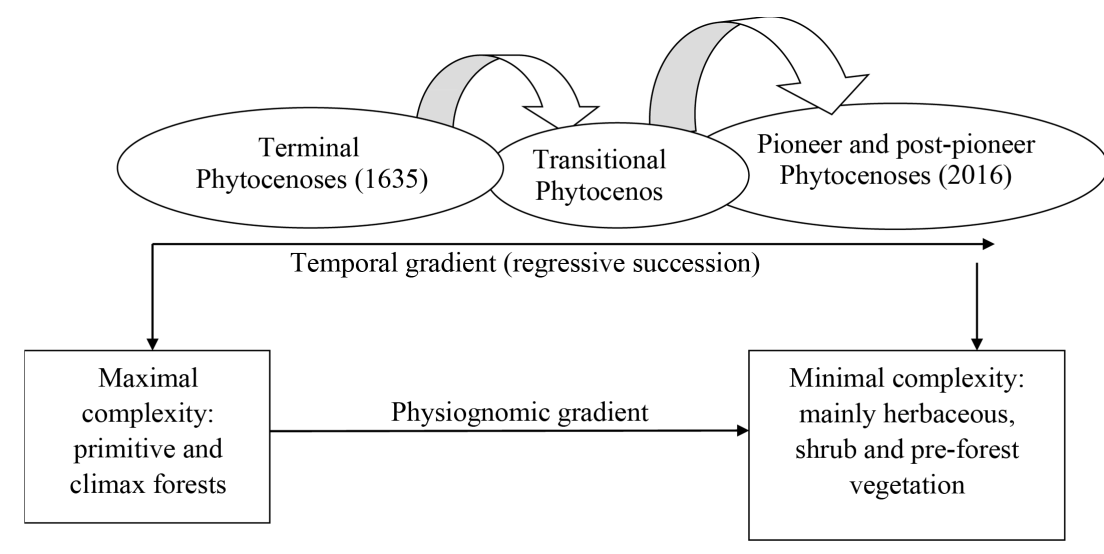

Figure 3. The present vegetation: A mosaic of ecological profiles. 
most significant are those that begin with the European settlement, whose evolution can be followed using the various historical documents. Since the beginning of the history of these islands, to the discovery of the Americas, a mass of scattered data has been produced and can likely allow us to trace the entire anthropization process. Although specific to each island component, the latter refers to a similar timeline. In the fertile imagination of the European discoverers, America's islands and particularly the Lesser Antilles had countless natural resources. To this fantasy vision of the time of their first arrival we must add the real opportunities to develop profitable farming crops of the tropical old world. These two previously mentioned elements have undeniably influenced the act of taking possession of the islands of Peru (the Antilles). The dynamics of anthropization used the same methods everywhere. The survival crops of the time of the first settlers were gradually substituted by a profit-generating agriculture linked to large plantations with dramatic consequences for the forest cover (Figure 4).

In Native American times, most of the forest formations were balanced or even "climax" forests. These first men, islanders, were hunters, gatherers and fishermen rather than farmers. Actually, the first descriptions of the Lesser Antilles landscapes suggest that their actions on the environment were marginal. While the dwelling groups developed, the environments' ecosystem vulnerability increased (Figure 5) and the highly specialised forest species declined in favour of the generalist ones characterizing open areas. The colonization brought notable

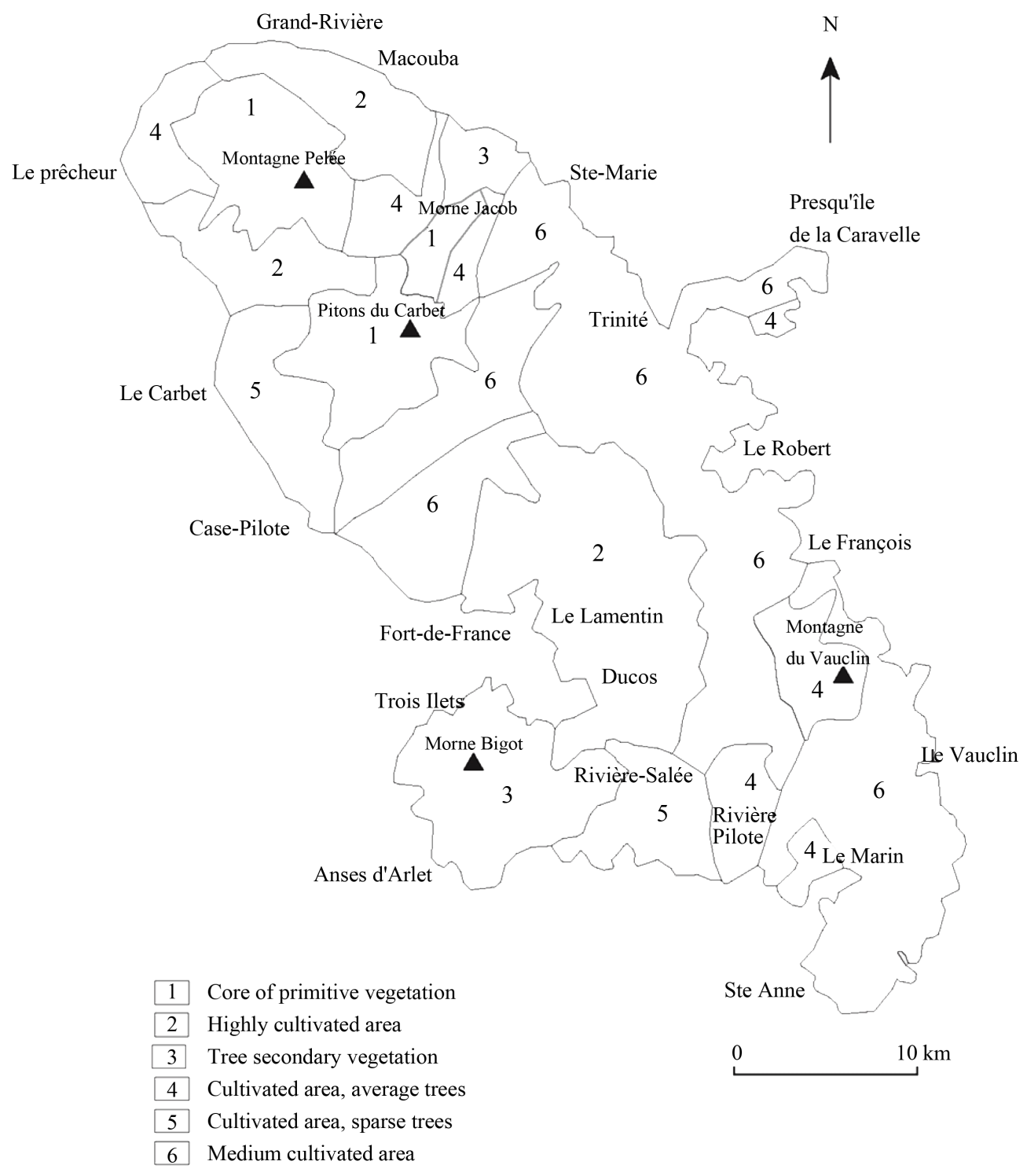

Figure 4. State of Martinique's vegetation cover around 1770. 


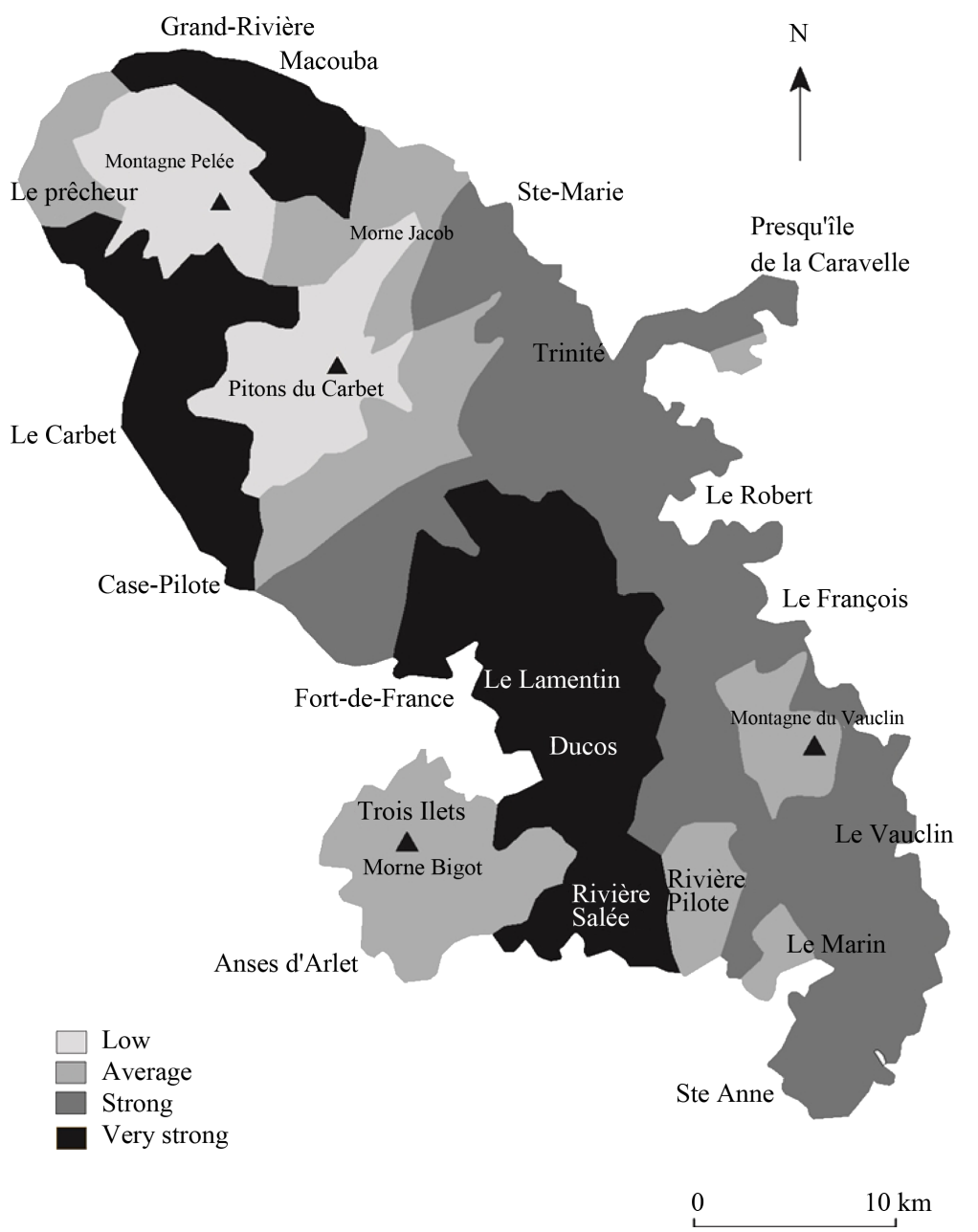

Figure 5. Martinique’s ecosystem vulnerability around 1770. (The climacic forest systems are the most resistant compared to the following elements: Hurricanes, soil erosion, invasive species. Overall vulnerability decreases from the climax stage (ecosystem resilience high) in the grass stage (ecosystem resilience low)/See Figure 7).

physiognomic changes within the plant cover. The morphological shrub and herbaceous types, once marginal types, supplanted the trees of the original forests. The invasion of native regressive taxa, (shrubs and herbaceous ones), subsequent to major deforestations due to agricultural development and selective harvesting, occurred globally in a few decades. Logically, the ecological dominance of shrub and herbaceous taxa increased due to the expansion of profit generating crops in principal the sugar cane. In precolonial times, they were certainly confined to biotopes or little abundant localized areas.

Today, these regressive or secondary species make up the different communities of the plant world of the Lesser Antilles. In reality, the establishment of phytocenoses typical of open areas in response to the first deep environmental decline is a valuable indication of the plant cover's flexibility. Additional destruction of the already "insularised" forest followed, notably at the end of the slave system. On most islands the former slaves who became workers in sugar cane factories and plantations occupied the upper third of the formerly wooded hills.

The arrival of the sugar beet on the world market sounded the death knell of the Lesser Antilles sugar cane, the main consequence being the disappearance of many homes and the spontaneous forest recolonization. The benefits of modernity through the use of fossil energy, specifically in the French Lesser Antilles, indirectly contributed to the natural reforestation of sectors serving as subsistence resources, where they found all the elements essential to the survival of their populations.

Things were not the same everywhere. On one side, the Islands considered the richest, such as the French 
ones, became more urban with the development of villages and the abandonment of agriculture. Rurality was inexorably the purview of the small peasantry and the large remaining export agriculture areas. This nature which has long been poorly treated seemed to be abandoned to itself and where possible it launched reconstruction processes. On the other hand, the greatest economic weakness of the British Lesser Antilles was the greatest poverty and the greater use of natural environments and particularly the remaining forests. All the forest elements were involved in the rural survival economy. Inevitably, between the French parts of the Caribbean and the other, the anthropogenic aggressions done to the ecosystems differed strongly and were directed to the floristic species, the biocenosis and the ecosystem. The consequences are difficult to assess, however they had to be serious in terms of loss of species, decreased population and the resilience inability of certain biosystems (mangrove forests, the plant understorey).

The first phase in the history of the Lesser Antilles is marked by a loss of diversity both at the level of forest plants and at the level of the landscape, direct and accurate ecosystem expression of the man-environment relationship. This profound anthropization phenomenon represents one of the first major ecological crises in the history of these lands (Figure 5). Very early, the resulting dramatic effects made themselves felt, such as soil erosion, declining soil fertility and the drying up of water sources mainly in the xeric areas [21].

The differences in development between the French islands and the majority of the English-speaking territories escalated with their "independence" and modernisation. Today, with regard to the forest and irrespective of the aspect considered, the differences are significant and their causes must be discovered in the urgent need of the respective rural populations to use all of the few resources offered by the forest environments: energy (charcoal), soil and microclimate (subsistence and profit-generating agriculture, agroforestry), wood (cabinetmaking, carpentry and constructions), traditional pharmacopoeia, hunting activities, drinking water (often untreated). In the old English dependencies, the often low population densities and the obligation to ensure, even if depleted, the renewal of the forest ecosystem allowed the rural population to maintain the minimum subsistence level. The development imperatives conserving a minimum of independence from the basic agricultural products and the water resources, the ultimate need to retain all biological diversity globally driven from Rio's Summit and the tourism's importance in the economy have made most of these micro-states commit to the protection of the strategic forest relics. As regards the French West Indies, the high human density and low land reserves of the municipalities represent a real hindrance to the global economic development (including all the sectors). However, the multiple laws and national and European directives on the protection of the environment have allowed us and will continue to allow us to conserve high ecological quality areas.

The historic anthropization of the Lesser Antilles, which in fact began with dwelling groups and plantations, provides an excellent study context for the understanding of the mechanisms of the vegetation's regressive or progressive evolution. In fact, from a hypothetical plant world characterized by a much higher ecosystem complexity than the current one and subdivided in space into specific forest sets, the centuries-long activities of the Antilles agrarian societies have resulted in the establishment of a plural flora mainly of the non-forest type (Figure 3). Logically, today's phytocenoses derive from the pre-colonial original forests [1] [2]. Their combinatory variability, the dominant morphological types, their ecology, phenology and dynamics must be linked to the heterogeneity of physical factors [56] [57], differences in temporal evolution, the selective pressure of human activities and the current richness of the plant species fund. The extreme difficulty is due to the decryption of subsidiary temporal and spatial relationships between these floristic entities. The specialists unanimously agree on the fact that in a vast majority of cases the disappearance of the anthropic pressure results in plant recolonization which could lead to the installation of forest communities, albeit in new configurations.

The various modalities of ecosystems restoration and restructuring are still operational, with regard to the anthropic pressure that is always varied in frequency and intensity. We can say that the plant cover of the Lesser Antilles which were highly anthropized at the beginning of this third millennium, are still resilient or maintain their regulation ability. The observable biocenotic mosaic is complex, since the constituent entities result from regression (often the nth degree of neo-regression) or progression mechanisms (often the nth degree of neoprogression). Human practices being different in space and in time, the vegetation's structural components exposed to human activities undergo permanent initiation and collapse processes. It is this original complexity accentuated by man's presence that is exciting and forms the basis of the scientific research. The Colons, the deported Africans and secondarily the Amerindians created landscapes on the basis of their relationships to the world and their vital needs highlighting the biophysical heterogeneities which were once smoothed out or faded by the high ecosystem structure of the forest environments. 


\section{Management}

The great ecosystem and floristic diversity and the significant socio-economic disparity resulting in unequal levels of development correspond to a plurality of modes of use of the space which currently characterizes the sector. The tropical characteristics of these small islands represents one of the development axes based almost exclusively on tourism. Sustainable or even mastered development would be managed by the ecology, economy and culture. Taking into account the inter-island differences in development, cultural practices and means of use of forest resources in the local economy, the environmental planning and management tools must be very specific. While taking into account the human influence, they must integrate two essential dimensions: firstly, the biological diversity (specific and biocenotic) at the level of each island and secondly the diversity of the entire Lesser Antilles.

Between the islands, the variations, although minimal, in the structure of physical factors (geomorphology, precipitation, soils, hydrology, topography, climate) result in characteristics of plant species distribution, therefore in their spatial distribution, in principal that of forest types. The anthropization enhanced these natural abiotic heterogeneities and operated qualitative and quantitative changes as well as changes in the ecosystem flora. Over time, under human pressure, the floristic dominance has been modified until the extinction of taxa. In this case, the problem of the plant material protection, irrespective of its degree of organisation, must rise to the level of the entire Lesser Antilles. If the geopolitical and economic unit is not fully effective, the floristic unity is a reality and must lead to unity in the intelligent management of flora and forest ecosystems. Compared to new global environmental data, this implies an implementation phase or even the harmonisation of the directives and laws applying to the various island components.

The inventory of floristic potentials of the forest formations with high ecological quality, the rare species of endangered or infrequent native trees and all the forest uses represent a vital and indispensable precondition. Subsequently, the study of the functioning of these heritage ecosystems will measure their vulnerability. In these territories more than anywhere else, the equation of sustainable development must be established primarily using economic, cultural, urban and infrastructural parameters as well as biocenotic ones.

In the light of the absence of economically exploitable material natural wealth, the future does not seem to encompass anything else than eco-development. Notwithstanding their low spatial importance, due to their floristic particularities, their strong involvement in maintaining biological balances and their ecosystem richness, the Lesser Antilles forests have undeniable characteristics to become conservatories of terrestrial biodiversity, in the least. Conservation will use various strategies, the goal being to preserve and enhance biological diversity, in principal the forest diversity.

The in-situ and ex situ protection of the original forms of recovery such as agroforestry, precious wood forestry, horticulture of native species for the parks and public and private gardens appear essential to ensure the sustainability of all physiognomic types and the communities they form. The protection procedures or methods must be determined to ensure a balance between biodiversity and the economic or cultural uses. But it is above all due to their intangible richness linked to some exceptional landscapes that the forest ecosystems will participate in the economic development (ecotourism).

Characterizing the current factors which cause problems, often resulting from conflicts of interest, is an unavoidable phase. The estimation of the anthropogenic constraints, city planning and rural development, is important in the long term for the establishment of planning tools integrating all the issues and concerns arising from the ultimate need to preserve the heritage areas and their biodiversity. More than today, the future management will have to be systemic and build from the hierarchical functioning of the biophysical environments. All elements as well as their interactive modalities will need to be considered. Two essential parameters will form the basis of the sustainable management programs: ecological conservation and the integration of human activities. The new management principles which will obviously emerge, will involve environmental vulnerability zoning (Figure 6) which will subsequently lead to space adjustments. In these tiny Caribbean Islands, the rural and the urban world are often two close and highly merged entities. Thus, we should define a hierarchy in the conservation and utilization of forest resources. The conservation could be assimilated to an exclusive preservation whose purpose would be the drastic spatio-temporal protection of the forest's biological diversity. We can also use the forest ecosystems in a conservative manner. This type of conservation would allow human or forestry activities for material or immaterial use if and only if the structural and functional forest changes do not jeopardize its resilience or regulation capacity.

The anthropogenic erosion of the biodiversity which is inexorably growing due to societal development will 


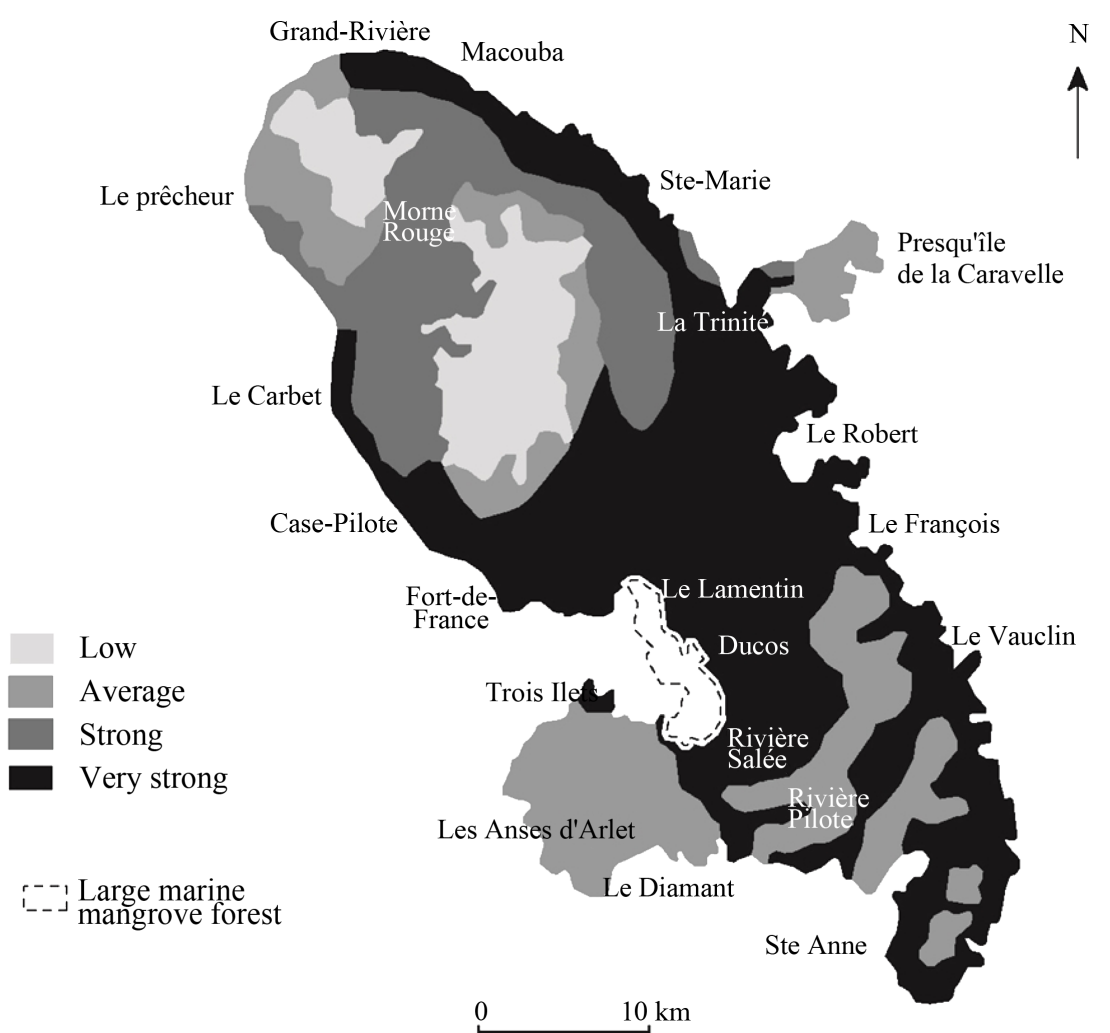

Figure 6. Ecosystem vulnerability in today’s Martinique. (The climacic forest systems are the most resistant compared to the following elements: Hurricanes, soil erosion, invasive species. Overall vulnerability decreases from the climax stage (ecosystem resilience high) in the grass stage (ecosystem resilience low)/See Figure 7).

deprive these island territories of the appropriate responses to the futures climate and telluric crises. More broadly, this loss of biologic diversity, both in floristic and ecosystem terms will be damaging to the world genetic heritage. Despite the lack of national and international interest which they currently engender, the Lesser Antilles forests can be considered in situ laboratories and represent a significant development factor. In the future, these ecosystem mosaics where the human imprint is uneven will without fail become ecological observatories, in principal for the complex processes of plant succession. The poverty of the research and scientific literature which still affects it today is a handicap for the implementation of effective management tools.

\section{Discussion and Conclusion}

The research in forest ecology and biogeography remains "unsaturated" to some extent in the Lesser Antilles. Naturalistic approaches highlighted the overall functioning of forest ecosystems. However, they do not allow us to understand all the dynamics at the scale of the species and the combinatorial mechanisms underlying a surprisingly large number of associations in a given bioclimate. In-depth autecological and synecologic studies are needed for a better understanding of the spatial and temporal vegetation organisation. This applies from the species to the plant community and from the most regressive phase of lowest complexity to the terminal phase of greatest complexity. The understanding of chorologic processes logically, requires knowing the structure of the main ecological factors, in principal the limiting factors.

The concept of bioclimate is no longer sufficient to describe even less to analyze the operation of plant covers. In addition to the rainfall water resource, we must take into account other factors whose variations significantly influence the installation of plant species and therefore the phytocenoses: Topography (exposure, containment, steep slopes), soil (hydromorphisme, structure, texture and physicochemical characteristics), hidden water resources (fog, dew), etc. The vegetation inversion phenomena linked to the complexity of factor networks associated with the different bioclimates make good research subjects. The modifier effect of the forest vegetation cover during a progressive or positive succession which has been little studied in the Lesser Antilles represents a 
research axis to develop. In fact, the scientific exploration of this phenomenon would explain the dispersion mechanisms of some species from their primary areas to their marginal areas [2].

Regarding the vegetation dynamics, if the milestones are currently well described, the multiple floristic facies identifying them are still poorly known. Given the presence of taxa of almost identical ecology, the stages or dynamic series are theoretically attested by several combinations of plant species. Depending on the bioclimates, and therefore on the plant floors, the floristic potential (the species stock or collection) typical for each island is divided into sub-potentials within which we can see all the ecological profiles. They have two primary functions:

1) The ability to colonize all or part of a plant floor (temperament in relation to a given bioclimate and, more broadly, to a defined factorial space, where in addition to the rainfall we take into account other environment factors).

2) The ability to develop populations in a temporal section or within a specific chronological sequence (temperament in relation to a specific factor generally the light whose intensity within the plant matrix depends on its closure or opening level, therefore on its evolution stage).

Depending on the floristic and anthropic history of the vegetation cover units and irrespective of the bioclimates, we can state that one approach is privileged within a field of possibilities. Schematically, the existing multiple floristic groups structuring the plant floors are successional intermediaries (transitional dynamic stages) positioning themselves differently on the temporal evolution gradient (Figure 7). The floristic specificity of these succession phases depends on the initial conditions, especially for diaspora availability. It is this mesh or this biocenotic temporally and spatially differentiated group that supports this significantly high plant biodiversity of the Lesser Antilles. It seems that in these parts, due to his centuries-long actions, man has made the plant world reveal all its flexibility, especially that of forest ecosystems.

The issue of sustainable development, compulsory for these islands, apart from all global considerations of plant resource conservation, is extremely complex. In this light, the relationship between populations and the ecosystems, particularly the forest ecosystems must be of such scope that at least they ensure their maintenance in their current
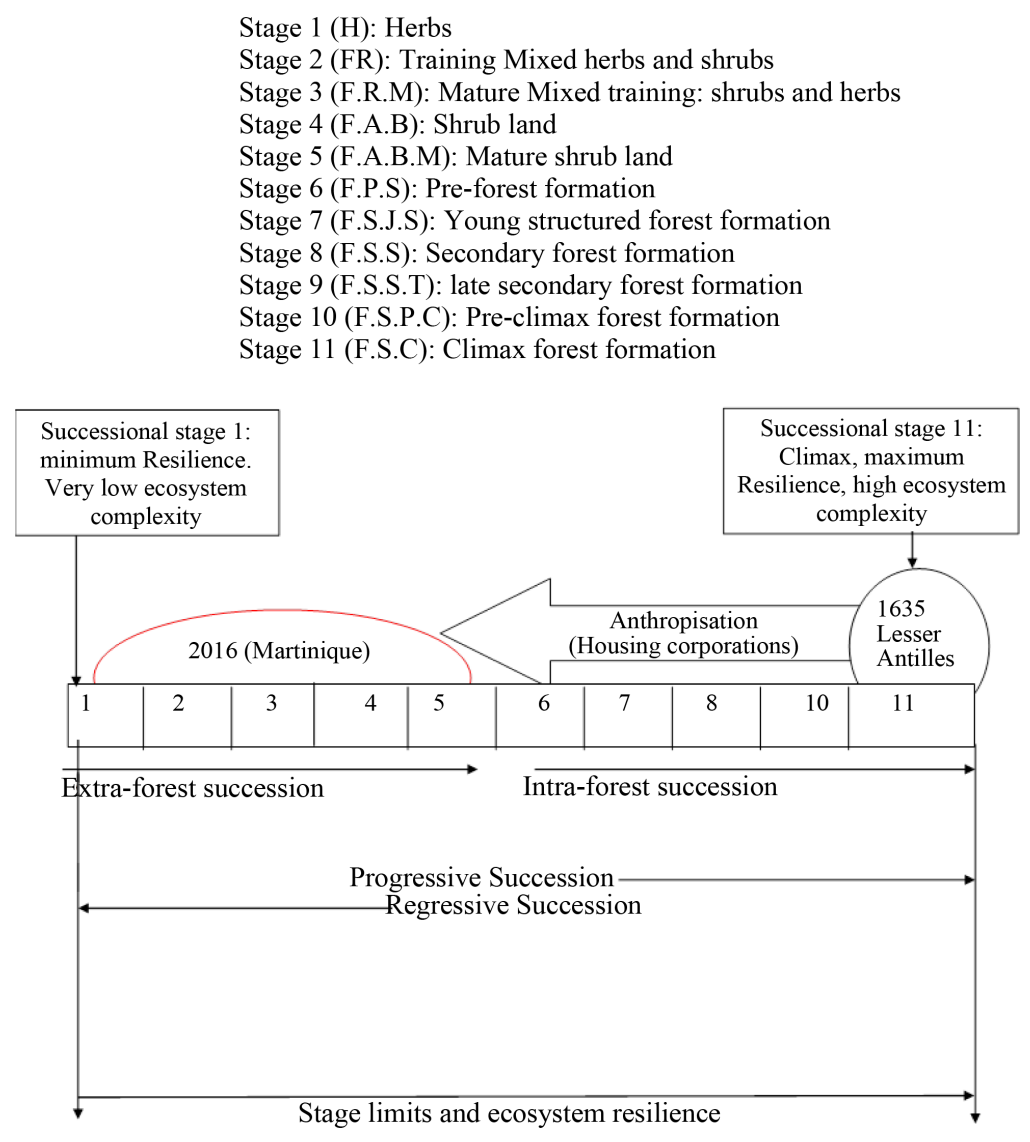

Figure 7. The dynamic gradient (vegetation succession). 
state and sometimes reinforce their biological diversity. Since all their aspects are essential to these island societies, in the future they will have to acquire both a material and immaterial dimension, enjoying the status of heritage objects more than they do today, inextricably associated to development tools or programmes.

In the smaller Antilles islands like in all parts of the artificialized biosphere, biodiversity is cyclical and is consubstantial with human activities. During humanity's development this biodiversity was often synonymous with resources emerging from a long and ongoing anthropogenic gardening of living things. Now, it remains to define, here as anywhere else in the world, the sufficient balance relationships between nature and men so that the genotypic plasticity is saved and also explored in order to improve the quality of life of human societies. Development, if it is to be sustainable, must internalize all societal dimensions. Finally, the means of occupation and use of the environments deeply differentiated in time and space are at the origin of this currently observable biodiversity. Despite the many anthropogenic extinctions of animal and plant species due mainly to harvesting or the disappearance of habitats, the living material, in this case the plants, remain essential for the future development. In the light of this reality, it seems important to consider any plant species as a true living being whose sustainability must be ensured by all means. Our goal here is not to place the Lesser Antilles in a protective casing. On the contrary, we wish to preserve, as necessary, the greatest possible biological diversity to address major environmental disasters as well as the age of human societies and geological time. In this light, there is no such thing as a small ecosystem because all the floristic, ecosystem and landscape expressions are consubstantial with biodiversity. The Lesser Antilles fully participate in the world's biological richness. Accordingly, in the light of conservation, restoration and development, their biological components must be defined as relevant objects of scientific research.

\section{References}

[1] Fiard, J.P. (1994) The Northern Forests of Mount Pelee and the Volcanic Edifices of Piton Mont-Conil and Morne Siberia. University Degree, Island Ecology and Management, Université Antilles-Guyane, Martinique, 595.

[2] Joseph, P. (1997) Dynamic, Plant Ecophysiology Dry Bioclimate in Martinique. Ph.D. Thesis, University of the Antilles-Guyane, 941.

[3] Moreau, J.P. (1987) A Filibuster in the Caribbean Sea: 1918-1620: Unpublished Manuscript from the Early Seventeenth Century. Publ. by J.P. Moreau, pref. J. Meyer, Clamart (France): Bibliographical Collection, 263.

[4] Thesse, F. (1989) Plée Auguste, 1786-1825, a Naturalist Traveler: His Work, His Tribulations in the Caribbean, Canada, Colombia. Paris, Ed. Caribéennes, 221.

[5] Pardon, N. (1877) The Martinique since Its Discovery until Today. Challamel, Paris, 367.

[6] Button, J. (1640) Relationship of the Establishment of the French since the Year 1635 in the Island of Martinique, One of America’s West Indies. Reproduction in Facsimile of the Paris Edition: CRAMOISY S. (1640), 141.

[7] Du Tertre, J.P. (1667) The General History of the Caribbean Inhabited by the French. Volume 1 \& 2, Containing Everything That Has Happened in the Establishment of French Colonies and Natural History. Ed Thomas JOLLY, Paris, 592.

[8] Ligon, R.A. (1657) True and Exact History of the Island of Barbados. Caribbeana: An Anthology of English Literature of the West Indies, London, 28.

[9] Rochefort, C. (1667) The Natural History of Antilles Islands of America. Volume 1. C. Fourmy, Lyon, 566.

[10] Breton, R.P. (1665) Caribbean-French Dictionary. Reissue of J. Platzmann, Leipzig, 1892, 480.

[11] Sloane, H. (1696) Catalogus plantarum quae in insula Jamaica sponte provenient. London.

[12] Sloane, H. (1725) A Voyage to the Islands Madera, Barbados, Nieves, S. Christophers and Jamaica: With the Natural History of the Herbs and Trees, Four-Footed Beasts, Fishes, Birds, Insects, Reptiles, \& C. Printed by BM for the Author, London.

[13] Plumier, C. (1693) Description of American Plants. Royal Printing House, Paris, 102 p.

[14] Plumier, C. (1705) Treaty of America Ferns. Imprimerie Royale, Paris, 146.

[15] Plukenet, L. (1691) Phytographia. Edited by the Author, London.

[16] Plukenet, L. (1696) Almagestum Botanicum Sive Phytographiae Pluknetianae [sic] Onomasticon. Published by the Author, London.

[17] Labat, J.B. (1705) Travel to the Isles. Adventurous Chronicle of Caribbean (1693-1705). Re-Issue Established in 1993 and Presented by Lebris, M., Paris, Phoebus, 463. 
[18] Hughes, G. (1750) The Natural History of Barbados? In Ten Books. Printed for the Author, London, 420.

[19] Jacquin, N.J. (1760) Enumeratio Systematica Plantarum, Quas in Insulis Caribaeis Vicinaque Americes Continente Detexit Novas, Aut Jam Cognitas Emendavit. Leiden. Reprint Nüremberg 1763, Facsimile Reprint of 1760, Edition Zug 1967. http://dx.doi.org/10.5962/bhl.title.100687

[20] Jacquin, N.J. (1763) Selectarum Stirpium Americanarum Historia. Wenen, Austria.

[21] Thibault Chanvalon, J.B. (1763) Travel to Martinique: Containing Various Comments on the Physical, Natural History, Agriculture, Customs and Travel the Island Made in 1751 and in the Following Years. Vol. 8, CI JB Bauche, Paris, 192.

[22] Vahl, M. (805) Enumeratio Plantarum 2. Copenhague, Danemark, 423.

[23] Ventenat, E.P. (1799) Table of the Plant Kingdom by the Method of Jussieu. Vol. 1, Drisonnier, Paris.

[24] Tussac, F.R. (1818) Flora of the Antilles or the General History of Botany and the Rural Countries: Economic and Native Plants of the Antilles, Exotic Plants Naturalized Are Described with the Sexual System of Linnaeus and the Natural Method of Jussieu, with Plates Drawn, Etched and Stained. Volume 2, Hautel, Paris, 221.

[25] Tussac, F.R. (1824 and 1827) Flora of the Antilles or General History of Botany and the Rural Countries: Economic native Vegetation of These Islands. The Exotic Plants Naturalized, Described as the Sexual System of Linnaeus and the Natural Method of Jussieu, Paris, France, Vol. 3, 121 (1824), Vol. 4, 121 (1827).

[26] De Candolle, A. (1855) Reasoned Botanical Geography: Or, Exposition of the Main Facts and Laws Concerning the Geographical Distribution of the Current Era of Plants. Vol. 2, V. Masson, Paris.

[27] Maycock, J.D. (1830) Flora Barbadensis. James Ridgway, London.

[28] Descourtilz, M.E. (1827-1829) Flora and Medical Picturesque Caribbean or Processed Conventional Plants in the French Colonies, English, Spanish and Portuguese. Chappron, Paris, France, Vol. 3, 370 (1827), Flight 4, 338 (1827), Vol. 5, 292 (1828), Flight 6, 308 (1828), Vol. 7, 344 (1829), Flight. 8, 472 (1829).

[29] Grisebach, A.H.R. (1864) Flora of the British West Indian Islands. Lovell Reeve and Co., London. http://dx.doi.org/10.5962/bhl.title.106964

[30] Duss, A. (R.P). (1897) Flora Phanerogamic of the French West Indies: Guadeloupe and Martinique. PROTAT Printing, Macon (France), 656.

[31] Ballet, J. (1896) The Guadeloupe: Information about the History, Flora, Fauna, Geology, Mineralogy, Agriculture, Commerce, Industry, Legislation, Administration. Basse-Terre, Government Printing, Vol. 1,2,3: 1625-1715, 369, Vol. 4: 1715-1774, 548.

[32] Lanessan, J.L. (1886) The Useful Plants of the French Colonies. World Exhibition in Antwerp, Paris, 86.

[33] Maze, H. (1892) Contribution to the Flora of Guadeloupe. The Government Printing, Basse-Terre, 191.

[34] Boldingh, I. (1909) The Flora of the Dutch West Indian Islands. PhD Thesis, Leyden-Brill, 594. http://dx.doi.org/10.5962/bhl.title.55966

[35] Urban, I. (1808) Symbolae Antillanae. Vol. 1. Frateres Borntraeger, Berlin, 5.

[36] Basse, N. (1886) Observations on Martinique. Printing Capiomont E. and Renault, V., Paris, 186.

[37] Beard, J.S. (1949) The Natural Vegetation of Windward and Leeward Islands. No. 21, Oxford Forestry Memoirs, Oxford, 192.

[38] Stehle, H. (1936) Ecology and Botanical Geography. Flora of Guadeloupe and Dependencies. The Printing House of the Government, Basse-Terre, 282.

[39] Stehle, H. (1938) Outline of Plant Associations of Martinique. The Printing House of the Government, Fort-de-France, 72.

[40] Stehle, H. (1947) The Sylvan Vegetation of the Caribbean Archipelago. Thesis of the Faculty of Sciences, Montpellier, 548.

[41] Howard, R.A. (1989) Flora of the Lesser Antilles, Leeward and Windward Islands. Vol. 5, Part 2, Harvard University, Jamaica Plain.

[42] Gooding, E.G.B., Loveless, A.R. and Proctor, G.R. (1965) Flora of Barbados. Her Majesty’s Stationery Office, London.

[43] Fournet, J. (2002) Illustrated Flora of Flowering Plants of Guadeloupe and Martinique. CIRAD and Gondwana Publishing, Montpellier, 1538.

[44] Stoffers, A.L. (1956) The Vegetation of the Netherlands Antilles. Studies of the Flora of Curaçao and Other Caribbean Islands, I, 142.

[45] Proctor, G.M. (1984) Flora of the Cayman Islands. Kew Bulletin of Additional Series XI. 
[46] Saint-Michel, M. (1652) Voyage in the Isles Camercanes in America That Are Part of the West Indies. Mans, Hierome Olivier, 434.

[47] Portecop, J. (1978) Plant Geography, Cartography and Ecological Development in a Tropical Island: The Case of Martinique. Thesis, University of Grenoble, Grenoble, 377.

[48] Pegler, D.N. (1983) Agaric Flora of the Lesser Antilles. Additional Series 9, Kew Bulletin, London, 1-668.

[49] Pegler, D.N. and Fiard J.P. (1983) Agaric Flora of the Lesser Antilles. HMSO.

[50] Chauvin, G. (1978) Illustrated Study of Families of Flowering Plants in Martinique: The Dialypetalous. The Documentary Books, CRDP-Antilles Guyane, 171.

[51] Chauvin, G. (981) Illustrated Study of Families of Flowering Plants in Martinique: The Apetalous. The Documentary Books, CRDP-Antilles Guyane, 61.

[52] Chauvin, G. (1985) Illustrated Study of Families of Flowering Plants in Martinique: Monocotyledons. The Documentary Books, CRDP-Antilles Guyane, 123.

[53] Rollet, B. (1969) Quantitative Studies of Moist Evergreen Forest of the Venezuelan Guayana. Thesis of State, University Toulouse-CNRS 2969, Toulouse, 404.

[54] Rousteau, A. (1983) One Hundred of Tree Seedlings of Guadeloupe. Morphological and Ecological Aspects. Thesis, University Pierre and Marie Curie, Paris, 249.

[55] Imbert, D., Bonhême, I., Saur, E. and Bouchon, C. (2000) Floristics and Structure of the Pterocarpus Officinalis Swamp Forest in Guadeloupe, Lesser Antilles. Journal of Tropical Ecology, 16, 55-68. http://dx.doi.org/10.1017/S0266467400001267

[56] Pagney, F. (1986) The Dry Landscapes of Guadeloupe: Aspects and Genesis. 2 Vols., PhD Thesis of 3rd Cycle, University of Bordeaux III, Bordeaux, 361.

[57] Pagney, F. (1989) The Dynamics of Vegetation in Dry and Sub-Humid Environment: The Example of the Guadeloupean Archipelago. Physio-Geo (Journal of Physical Geography and Environment), 19, 5-14.

\section{Submit or recommend next manuscript to OALib Journal and we will provide best service for you:}

- Publication frequency: Monthly

- 9 subject areas of science, technology and medicine

- Fair and rigorous peer-review system

- Fast publication process

- Article promotion in various social networking sites (LinkedIn, Facebook, Twitter, etc.)

- Maximum dissemination of your research work

Submit Your Paper Online: Click Here to Submit

Contact Us: service@oalib.com 